\title{
Sentido místico da tradição da tragédia nos povos da floresta amazônica: $O$ dionisíaco nietzscheano como impulso criador resguardado no relato etnográfico de The Odor Koch-Gruberg do ritual de danças e máscaras da tribo Kobéua
}

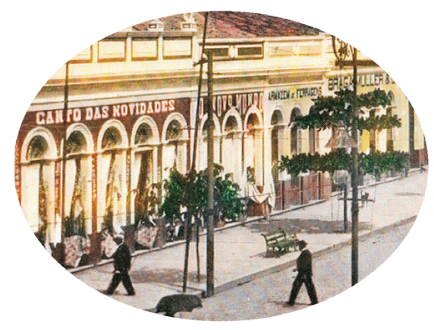

Agenor Cavalcanti de Vasconcelos Neto

\section{Resumo}

Por meio das obras A Origem da Tragédia, de Nietzsche, e Dois anos entre os indígenas, de Koch-Grunberg, identificamos o instinto dionisíaco na tragédia grega, que em paralelo com as impressões etnográficas da última obra ao descrever os rituais do Alto Rio Negro, nos deixa espaço para um estudo comparativo das manifestações com máscaras Kobéua para uma confirmação estética contemporânea do místico e do trágico.

Palavras-chave: Trágico; máscaras; filosofia da antropologia.

\begin{abstract}
Through the work The Birth of Tragedy, by Nietzsche, and Two years among the Indians, by Koch-Grunberg, identified instinct Dionysian in Greek tragedy, in parallel with the impressions of the last ethnographic work to describe the rituals of the upper Rio Negro leaves us room for a comparative study with shades of manifestations Kobéua contemporary aesthetic for a confirmation of the mystical and the tragic.
\end{abstract}

Keywords: Tragic; masks; Philosophy of Anthropology.

\footnotetext{
* Mestrando em Sociedade e Cultura na Amazônia pela Universidade Federal do Amazonas. E-mail: agenor7@hotmail.com
} 


\section{Introdução}

Dois anos entre os indígenas é um documento de valor etno-histórico e, além disso, uma obra norteada por critérios estéticos, literários, fotográficos e iconográficos, segundo os moldes de um gênero literário antigo, caracterizado como relatos de viagem. É resultado do período que a Völkerkunde (numa tradução livre, significa etnologia) surgia na Alemanha como projeto científico, e que só posteriormente ganhou status acadêmico, com as duas bem-sucedidas expedições de Koch-Grünberg (FRANK, 2005, p. 572). A primeira realizada no período de 1903 a 1905, ao Alto Rio Negro, noroeste do Brasil, cujo relato é o nosso objeto. A segunda partindo da foz do rio Branco até o rio Orenoco, passando pelo Monte Roraima, na Venezuela de 1911 a 1913.

Dessas expedições, além de se ter inaugurado a Antropologia moderna na América do Sul, temos, pela primeira vez, uma definição da paisagem étnica de regiões antes inexploradas e que a disciplina de hoje segue ainda mais ou menos esse modelo. Aqui, nos deparamos com a seguinte questão: a evidente motivação estética de Koch-Grünberg, e seu interesse tanto pelo papel da arte na cultura dos indígenas visitados nessa expedição de 1903 e a sua atenção especial em documentar as danças de máscaras, sem se esquecer do registro das pinturas corporais e adornos em geral.

O interesse especial pela arte é um princípio norteador das viagens e pesquisas etnográficas presentes nos relatos de Koch-Grunberg. É bom lembrar que, não só temos a arte em evidência, mas também a organização social, a linguagem, a geografia, etc.. Porém as manifestações estéticas indígenas, juntamente com o interesse de nosso etnógrafo, tem relação direta com a formação do pensamento antropológico e a prática etnográfica na América Latina.

Destarte, no texto de apresentação da edição disponível em nosso idioma da obra Dois anos entre os indígenas, o Prof. Dr. Renan Freitas Pinto mostra o interesse do nosso etnógrafo para com a Arte:

Um dado bastante significativo quanto ao seu interesse especial devotado à arte dos povos indígenas da Amazônia é o de haver escrito um livro intitulado Anf änge der Kunst im Urwald (começos da arte na floresta) obra publicada 
em 1906 e que ainda espera ser traduzida para a língua portuguesa, o que muito contribuirá para evidenciar o papel que possuía a arte indígena para a formação do pensamento antropológico sobre os indígenas por ele estudados (PINTO, 2005, p. 14).

No entanto, com o intuito de servir ao Museu de Berlim no enriquecimento do seu acervo, ele conseguiu reunir diversas peças etnográficas, dentre elas, claro, as de natureza artística. Seu interesse, portanto, mostra-se dividido entre o de um colecionador e de um cientista imbuído de identificar as manifestações artísticas dos grupos estudados:
É, portanto, necessário reconhecer que sua obra dedicou uma atenção especial ao significado da arte para os povos indígenas, sendo possível através da documentação que reuniu e organizou nesse particular, identificar não apenas a complexidade de algumas dessas manifestações estéticas, mas a grande riqueza cultural dessas tão diferenciadas formas de expressão artística dos povos indígenas (PINTO, 2005, p. 14).

Ocuparemos-nos aqui com a descrição do ritual de máscaras dos Siusí e dos Kobéua que nos foi transmitida pela etnografia de um Bildungsbürger ${ }^{1}$ alemão, na obra Dois anos entre os indígenas, em sua especial atenção à arte, a fim de a interpretarmos na perspectiva da estética nietzschiana, fundamentada em outra linha de conhecimento. Friedrich Nietzsche vasculhou a cultura grega para encontrar na origem da Tragédia o sentido do deus Dioniso e elaborou um tratado antropológico pessimista estético que pretendemos comparar com as manifestações artísticas registradas no decorrer da viajem de KochGrünberg pela Amazônia brasileira. O duelo entre as motivações institucionais de um colecionador versus o interesse de um cientista nas concepções mais profundas da cultura dos grupos visitados são consideradas pelo próprio etnógrafo em seu relato:

Mas para mim o objetivo principal da minha viagem não era o de um colecionador. Freqüentemente demorandome semanas, até meses em cada tribo, e em cada aldeia, 
participando intimamente da vida dos indígenas, eu pretendia especialmente conviver e aprofundar mais a visão de suas concepções, pois o viajante que passa rapidamente pela região de suas pesquisas consegue apenas impressões passageiras e freqüentemente falsas (KOCH-GRUNBERG. 2005, p. 7).

\section{O interesse especial de Koch-Grunberg pelas máscaras}

Havendo ressalva quanto ao seu intuito de colecionador, não podemos deixar de perceber seu interesse pela visão e concepção, por que não, cosmovisão do seu objeto de pesquisa. A aporia entre as concepções de mundo de nosso etnógrafo e das sociedades tradicionais da região, diz respeito a essa dificuldade de se descrever as concepções de uma cultura mítica a partir da cultura do homem moderno, homem científico. Para isso, Koch-Grunberg tentou uma vivência num mundo segundo a tradição dessas tribos visitadas, tradição de teor mítico. Sua principal comunicação com essa linguagem mítica é por meio do contato com as celebrações rituais, que são o ápice de significação do mundo na cultura mítica, atingindo toda sua força de expressão, através da tensão, como nos orienta Socorro Jatobá, entre Memória e Palavra:

É na tensão permanente entre esquecer e lembrar que vigem
as sociedades tradicionais, os povos que têm na atividade
de narrar um poderoso mecanismo de preservação de uma
sabedoria milenar e de renovação constante de um imenso
e vasto repertório de histórias que revelam uma experiência
com o mundo em tudo diversa da nossa atual experiência
de mundo. Onde as palavras são vistas como mecanismos
de mediação entre homem e mundo.Nosso trabalho é
sobre um outro modo de compreensão da realidade. Uma
compreensão da realidade tecida pacientemente pelas
palavras em narrativas que emprestam, que atribuem sentido
ao mundo (JATOBÁ, 2001, p. 25).

Segundo seu relato de viagem, após seu deslocamento de Manaus ao Alto Rio Negro, Koch-Grunberg penetra no rio Içana em busca de seus objetos de estudo. No Capítulo IV, intitulado Viagem subindo pelo rio Içana até 
Tunubý, surge, despretensiosamente, a descrição de seus métodos de coleta dos objetos etnográficos. A maioria das vezes negociava com os indígenas em troca de mercadorias das quais tinha se abastecido exatamente para esse fim: [...] tabaco, pequenas facas, anzóis, fósforos, espelhos, miçangas, e outras futilidades, preciosas para os indígenas (KOCH-GRUNBERG. 2005, p. 74). Por outro lado, às vezes encontrava aldeias inteiras abandonadas, ricas em utensílios artisticamente ornamentados que eram prontamente recolhidos pelo nosso pesquisador alemão, como se constata no trecho: "Aquartelamo-nos com toda bagagem em uma das casas vazias que estava cheia de potes belamente pintados, belos produtos de arte artesanal local" (KOCH-GRUNBERG, 2005, p. 70).

Ao chegar a Tunuhý, última parada antes de subir o rio Aiarý, temos que dar especial atenção à passagem que se refere aos “indescritíveis utensílios indígenas: caixas, maletas, vasilhas belissimamente pintadas, cestos, armas de fogo, carauatanas, cultura e selvageria numa confusão completa"(KOCHGRUNBERG, 2005, p. 73, grifo nosso).

Ao subir o rio Içana, na parte baixa do rio, as aldeias estavam desabitadas por conta de movimentos messiânicos que estavam acontecendo na região $(\mathrm{KOCH}-$ GRUNBERG, 2005, p. 75), e os objetos eram recolhidos sem permissão de seus verdadeiros donos. Quando as aldeias estavam ocupadas, assim se procedia à compra:

Então conforme o método já experimentado dei à criancinha uma grande pérola azul, de presente provocando um agrado geral. A pérola foi logo amarrada no pescoço da criança. E o gelo quebrou-se! Começou o negócio. Eu remexi nas palhoças e ajuntei logo uma pequena, mas, valiosa coleção de camutis (potes para água) e pratos em forma de taça que tinham apreciáveis desenhos pintados de vermelho, balaios que tinham semelhantes desenhos trançados em preto; uma gingantesca carauatana (tubo para soprar flechinhas) de $3 \mathrm{~m}$, com as correspondentes flechinhas enfiadas em uma aljava que também estava trançada com lindos desenhos; alguns potezinhos com o pernicioso veneno de cucare e ainda outras belas coisas. Essa boa gentinha sacudia-se de tanto rir, por causa desse estranho negócio. Eles aparentemente me consideravam um pouco doido, porque até então ainda 
nenhum branco tinha ido ao meio deles, desejoso de tal tralha, e a seu ver pagando tão excessivamente $(\mathrm{KOCH}-$ GRUNBERG, 2005, p. 73).

Mais adiante em seu relato, Koch-Grünberg chegou à maior aldeia Siusí, chamada Cururú-Cuará (Buraco do Sapo), onde encontrou muita gente. Aqui, foi sensibilizado acerca das primeiras máscaras, o que o motivou sua busca sobre as danças, cantos e mitos do ritual de máscaras. Apesar de haverem muitos Siusí possuidores daqueles objetos, eles se mostraram bastantes indispostos a negociar, mesmo com o já descrito método de troca, o que vai de encontro à generalização dessa prática por parte dos indígenas, que transparece no tom utilizado na descrição das primeiras trocas: "Eles aparentemente me consideravam um pouco doido, porque até então ainda nenhum branco tinha ido ao meio deles, desejoso de tal tralha, e a seu ver pagando tão excessivamente" (KOCH-GRUNBERG, 2005, p. 73). Assim, ficando mais à mercê da sorte do que das trocas de mercadorias para a coleta de seus objetos, eis que, pode-se dizer, a sorte surgiu para nosso cientista viajante:

A gente do Cururú-cuara demonstrava pouca disposição para negociar. Raramente alguém trouxe alguma coisa espontaneamente para vender. Quase tudo que obtive foi conseguido indo pelas casas e procurando coisas. Em um canto escuro, achei com muita alegria, em um jirau, duas máscaras belíssimas, já totalmente empoeiradas, que estavam bem conservadas, apenas com poucos defeitos. O revestimento do tronco era trabalhado de entrecasca vermelha e estavam inseridas nos buracos para os braços. Longas faixas de entrecasca amarela pendiam das mangas e na parte inferior do revestimento do corpo. Uma das máscaras representava a borboleta, makálu, a outra representava a lagarta, ákoro, como Mandú explicou. Elas provinham dos Káua-tapuyo, que viviam em algumas grandes malocas rio acima. Lá deveria haver mais dessas máscaras. Decidi, depois que chegar o Schmidt, subir logo pelo rio Aiarý até onde seria possível viajar, para continuar procurar seguindo esta interessante descoberta etnográfica (KOCH-GRUNBERG, 2005, p.102). 
Essa interessante descoberta etnográfica nos leva a afirmar que o motivo de sua viagem, ao menos na subida pelo rio Aiarý, é redirecionada, ansiosamente, pelas manifestações artísticas dos indígenas.

No dia 26 de outubro de 1903, nos seus últimos dias em Cururú-cuara, entre os índios da etnia Siusí, toda maloca e seus hóspedes, entre eles, KochGrünberg, foram a uma festa com dança, rio abaixo, em Atiaru (KOCHGRÜNBERG. 2005, p. 109). Na descrição do festejo vemos nitidamente, seu interesse pelos objetos da cerimônia. Era do Alto Aiarý que provinham as máscaras encontradas, segundo Mandú, informante do pesquisador, como no trecho citado anteriormente, que se refere à interessante descoberta.

Como planejado, a comitiva de Koch-Grunberg parte rumo Alto Aiarý após a festa de danças descrita, e noutra recepção de boas-vindas KochGrünberg é tocado pelo apelo estético dos Káua:

A espaçosa maloca estava situada no alto da margem direita. O revestimento de cascas da frente da casa estava pintado com figuras simétricas de cor preta-branca-vermelhaamarela e testemunhava já o sentido artístico dos habitantes, que se manifesta especialmente na confecção de vestimentas de máscaras ornamentadas com padrões coloridos (KOCHGRUNBERG, 2005, p.140).

O objetivo de buscar a fonte da interessante descoberta das máscaras foi alcançado ainda no primeiro volume de sua obra, ficando claro o fato de ter sido motivado pelo teor artístico dos objetos etnográficos em algumas decisões na sua pesquisa, principalmente na composição do roteiro de viagem. Como observamos, entre os Kauá, segundo o relato, há um registro de grande acréscimo à coleção etnográfica:

A coleção etnográfica recebeu aqui bastante acréscimo, especialmente de utensílios caseiros e objetos de adornos. Os colares mais belos, nós os encontramos entre as crianças. Os pais querem demonstrar externamente seu amor idolatrado para com os da casca dura de vários frutos de palmeira, ossinhos de tartaruga terrestre, yabutí, mãozinhas de gente, graciosamente esculpida do casco do mesmo réptil, 
dentes de vários, animais, como onça, javali, jacaré, macacos e outros estavam enfiados junto com miçangas coloridas, em uma ordem de bom gosto sobre fios de fibras de palmeiras. Semelhantes enfiadas de nozes e frutas de palmeiras como chocalhos estavam amarrados no tornozelo das crianças menores (KOCH-GRUNBERG, 2005, p. 149).

Nesse ponto da expedição, após a recepção cerimonial que devia passar em todas as malocas, Koch-Grunberg pôde desenvolver mais profundamente a interessante descoberta das Máscaras dos Kauá:

Nossa vinda tinha sido no tempo favorável: depois de dez dias, deveria ser realizada a festa com danças de mascarados, uma festa fúnebre, em comemoração ao finado, porque as danças de mascarados somente são realizadas em tais circunstâncias tristes (KOCH-GRUNBERG, 2005, p.151).

O dilema oriundo da relatividade do juízo da experiência estética, de um lado, e a formulação de um sistema objetivo que nos esclareça logicamente esse material instável de sensações voláteis que se aplicam ao estudo das relações entre a arte, o conhecimento e a natureza (SUASSUNA, 2007, p. 27), está claro na descrição do método arcaico da antropologia de Koch-Grunberg. Ao tentar formular um sistema objetivo que compreenda o papel da arte na cultura indígena, ou pelo menos exigi-lo, perpetuam um caos desnecessário, segundo Ariano Suassuna:

É à Filosofia que temos de recorrer quando discutimos se a Arte pode ser aristocrática, isto é, dirigida a uma elite espiritual, ou se qualquer Arte que não vise à educação de um Povo (ou não esteja à altura de ser por ele entendida e aceita) é por natureza condenável. É também da Filosofia que temos de nos valer para estudar se a Arte é um jogo ocioso e gratuito, ou não; se a Arte é uma forma pura de deleitação e de prazer estético, ou se deve obrigatoriamente ter objetivos didáticos, de natureza ética, religiosa ou política; as relações da Arte com o Estado e o Poder, com a moral e com a Ciência - tudo isso só pode ser estudado do ponto de vista filosófico (SUASSUNA, 2007, p. 359). 


\section{Koch-Grunberg e a tradição científica alemã}

Definiremos como contexto da fonte antropológica em questão o que se passou a chamar de Völkerkunde: tradicional escola regional alemã de molde científico cultural e social, numa definição neo-kantiana de antropologia (FRANK, 2008, p. 130). O esboço desse projeto etnográfico foi definido por outro Völkerkunlder, no fim do século XVIII, segundo nos explica Frank:

Antropologie (Esboço de uma Antropologia Comparativa; cf. Bunzel,1996). Nesse trabalho, Humboldt argumenta que o Gattungscharakter da humanidade, isto é, o caráter da humanidade como espécie realiza-se historicamente em uma variedade quase ilimitada de Nationalcharaktere (plural de caráter nacional) ou Volkscharaktere (caracteres de povos) que, por sua vez, se refletem diretamente nos costumes, nas crenças, na língua e nas artes de cada povo e época (FRANK. 2005, p. 565).

Como um Bildungsbürger, ${ }^{1}$ pertencente a uma classe que acredita no Bilbungsideal, ${ }^{2}$ nosso etnólogo fazia parte de um bem-definido meio social e cultural, segundo nos assegura Erwin Frank. Koch-Grünberg escrevia para um público moralista, cheio de preconceitos, e ao escrever tentava corrigir a visão de seu estereotipado leitor:

É claro que as freqüentes ironias, as alusões a valores éticos e estéticos e ao hábito, assumiu como as raras e bastantes cuidadosas tentativas de corrigir certos preconceitos do seu leitor imaginado, principalmente com relação à "natureza" dos índios e a vida nos trópicos (FRANK, 2008, p. 128, grifo nosso).

Podemos esboçar, grosso modo, que o fim a que se destina a realização da Völkerkunde é a busca da Gattungscharakter, ou seja, o caráter da humanidade, por meio da análise comparativa das Volkscharaktere, caracteres específicos de cada povo: 
Mais concretamente, Von Humboldt propõe que se estudem os condicionamentos metafísicos do espírito humano (o Gattungscharakter, uma idéia profundamente kantiana em roupagem terminológica herderiana, por meio da observação empírica, holística e não reducionista, de seus efeitos sobre os diversos Volkscharaktere em contextos histórico-ambientais distintos (FRANK, 2005, p. 565-566).

Nesse sistema de essência kantiana, que visa a obtenção de dados empíricos, proveniente das peculiaridades de cada povo, em terminologia alemã Volkscharaktere, deveriam desvelar "universais" da humanidade num plano metafísico, geral, segundo a idéia do Gattungscharakter alemão. Encontramos aqui, a aporia epistemológica entre o reducionismo positivista do Iluminismo e das Ciências Naturais e o holismo, culturalismo romântico alemão, em outras palavras:

Como vimos, essa interpretação da cultura-educação como uma força moldadora e unificadora por trás das ações, das idéias e dos valores dos integrantes de qualquer povo e, por meio destes, também dos seus produtos (materiais e imateriais) opõe-se frontalmente à tentativa dos iluministas e positivistas da época de identificar uma ética e uma estética, um único estilo de vida humano universal como objetivamente e exclusivamente racional civilização (FRANK, 2005, p. 569).

\section{O ritual de máscara dos kobéua e o dionisíaco nietzschiano}

Confrontaremos dois aspectos do ritual com as categorias estéticas metafísicas propostas por Nietzsche de apolíneo e dionisíaco, com foco nesta última, em dois momentos distintos da cerimônia Kobéua: o princípio, onde se iniciam as honras fúnebres e começam os ritos de encarnação dos demônios da floresta, corporificados nas máscaras, onde percebemos elementos apolíneos; e o ápice, no qual as danças se transformam em representações falóforas, quebrando todo ritmo pedagógico da descrição do festejo fúnebre.

O falo nas culturas tradicionais e religiões arcaicas é adorado pelos 
antigos, acima de tudo, como símbolo da fecundidade da natureza. Tomemos, pois, as primeiras considerações sobre o ritual de Danças e Máscaras do povo Kobéua, segundo o relato do etnógrafo: "um rito de honras fúnebres em que se encarnam demônios da floresta, cerne do teor mítico-trágico do ritual" (KOCH-GRUNBERG, 2005, p. 506).

$\mathrm{Na}$ metafísica estética proposta na Origem da Tragédia, de Nietzsche, a embriaguês do estado dionisíaco possibilita tocar o conhecimento por outras vias. A cultura que prima pelo dionisíaco da sua arte pretende estar em contato direto com o conhecimento, a verdade do mundo, a sabedoria de Sileno. Segundo o filósofo, depois de apoderar-se de Sileno, o rei Midas perguntou qual dentre as coisas "o homem deveria preferir e a tudo considerar sem par", a resposta do semi-deus:

"Raça efêmera, e miserável, filha do acaso e da dor! E tu, porque me obrigas a revelar-te o que mais te valeria ignorar? O que tu deverias preferir não o podes escolher: é não teres nascido, não seres, seres nada. Já que isso te é impossível, o melhor que podes desejar é morrer, morrer depressa" (NIETZSCHE, 2007, p. 51).

O impulso apolíneo torna a vida plausível, suportável através da aparência: como num sonho suportamos a vida, visto que, no transe apolíneo não se afigura diante de nós nada além do que profundidade da sabedoria dionisíaca pela aparência. Isso nos revela um princípio de objetivação da metafísica do mundo. Devemos, pois, transpormos a essa outra realidade não individualizante, a que se chega através do abismo não materializavél da potência dionisíaca, para compreendermos a dualidade original da arte proposta pelo filósofo alemão.

Primordialmente é o teor fúnebre do ritual de Danças e Máscaras Kobéua em paralelo com o ponto trágico da existência humana, revelado na obra $A$ Origem da Tragédia, de Nietzsche, que nos chama a atenção: fundamentando-se na antiga cultura grega para desvelar a sabedoria de Sileno, ${ }^{3}$ o filósofo aponta a necessidade do enfrentamento da natureza apolínea com a natureza dionisíaca da arte em representações trágicas.

Nesse ponto se pode tecer uma rede de relações entre a sabedoria de Sileno que engendra a força dionisíaca com o teor fúnebre do rito; entre a dor original e a descrição de Koch-Grunberg dos cantos de lamentação do ritual 


\section{Kobéua.}

Paralelamente, o ritual fúnebre de Danças e Máscarasé sempre comemorado por ocasiões desse aspecto horrível da existência, é simbolicamente o reencontro do indivíduo com a natureza, mas, enquanto ser individual, o Kobéua morto se reintegra ao universal da natureza, num outro prisma, os que celebram as danças tentam fazer o sentido inverso do morto. Buscam trazer por meio de materializações artísticas de danças e máscaras, que são praça da aldeia, por meio da aparência das Máscaras:

O sonoro uivo de lamentação de ambas as mulheres, aos poucos, transformou-se em canto fúnebre, melodioso, acompanhado de soluços, e esmoreceu aos poucos. Os espectadores estavam quietos. As mulheres tinham rostos espantados. Duas meninas tinham até trepado rapidamente em um jiráu. Depois de terminada a dança, todos riram de novo, em uma confusão barulhenta, inclusive as duas mulheres que sentadas de cócoras no chão ainda agorinha tinham se lamentado, chorando amargamente e soluçando, escondendo o rosto entre as mãos (KOCH-GRUNBERG, 2005, p. 158).

O segundo ponto é ápice do ritual onde há um estágio de real naturalização do homem percebido, não somente nas Danças de Máscaras, imagem primeira do ritual, mas, na sobrepujança de danças fálicas advindas dos próprios demônios encarnados, para numa simbologia mágica representar a fertilidade da aldeia e da natureza, o que nos revela uma cultura de natureza dionisíaca resguardado num relato de nossa cultura socrática, do homem teórico, por meio de Koch-Grunberg.

A segurança almejada pela cultura socrática do conhecimento se confirma por meio de verdades objetivantes, parcializadas, o que reduz possibilidades de abrangência das pequenas perspectivas rumo a um horizonte mais amplo, como o do conhecimento estético. Segundo Nietzsche (2007), a ciência moderna ilustra, dentro desse contexto, o mais alto grau de socrática valoração da vida, da justificativa ideal para a existência do homem: pode-se dizer que é atualmente a religião em voga perante o vazio do existir (p. 49).

Para compreender o contraste apolíneo frente ao impulso dionisíaco, princípio dicotômico estético, essencialmente metafísico, proposto por 
Nietzsche no ensaio sobre a origem da tragédia grega, faz-se necessário desfazer o olhar teórico predominante na cultura atual, impregnado nas impressões do etnólogo Koch-Grunberg, visão fragmentária e individual, que tem o tom do Nada em demasia e Conhece-te a ti mesmo, inscrições do oráculo de Delfos, dedicadas a Apolo, que buscam consciências bem delimitadas sobre assuntos bem específicos.

No estado emocional contagiante que se segue ao início do rito entre os Kobéua, com a invasão da praça da aldeia pelos demônios da floresta, descrito no trecho que nos revela a introdução da honra fúnebre, é relevante a referência filosófica pessimista, o teor cruel da existência proposto por Nietzsche por meio da sabedoria de Sileno, encontrada por ele no povo grego, e que também nos é resguardado na descrição do ritual Kobéua:

Também entre os Kobéua, as festas dos finados são ocasiões para danças de máscaras. Estas começam pelas três horas da tarde, com a mesma introdução dramática, como no Aiarý. As máscaras saem da beira do rio e atacam a maloca, enquanto as outras máscaras a defendem sem sucesso. As danças de máscaras duram até a manhã seguinte. Depois, penduram as máscaras sobre hastes, na praça da aldeia, amarram-na pelas mangas, usando as franjas de entrecasca, e tocam fogo nelas (KOCH-GRUNBERG, 2005, p. 505).

Observando o material registrado e fotografado pelo etnólogo, se verifica a não predominância do impulso apolíneo nessa cultura, basta comparar os simétricos traços da pintura de um Rafael aos traços das máscaras que encarnam os demônios, assim como a atitude de cremação das máscaras após o rito. De todo modo, o que nos interessa é que por trás dessas manifestações apolíneas da arte está, seguramente, o encontro do homem com sua mais profunda natureza não individualizante: primeiro, pela metamorfose que o uso da máscara implica (BURKERT, 1993, p. 217); segundo, a dança como materialização corporal da metafísica musical, chegando ao cume na dança de falos. Koch-Grunberg salienta a relação da máscara com mundo metafísico dos Kobéua:

É nas danças de máscaras que se exprime esta busca do causador corpóreo de todos os espíritos com a sua seqüência 
de animais da água, da terra e do ar, que representam os demônios (gênios) e cada classe de animais, até com excelente mímica (...) O demônio está dentro da máscara, está incorporado nela; para o indígena, a máscara é o demônio (KOCH-GRUNBERG, 2005, p. 506).

Desse modo, demônios Kobéua são manifestações da natureza, do todo, em sentido universal, no objeto individual, particular da arte da máscara, na tentativa de encarnar a vontade totalizadora da natureza por meio de um ritual dançante mascarado em personificações individuais dos gênios da floresta, ou como nos explica Burkert sobre essa metamorfose, "O sinal exterior e o instrumento da metamorfose provocada pelo deus é a máscara. A fusão entre o deus e o seu adorador que ocorre durante esta metamorfose não tem paralelo na religião grega. Bacchos é o seu nome, tanto de um como do outro" (BURKERT, 1993:318).

Relacionamos, tanto nessa, quanto na outra passagem, sobre o início do canto fúnebre, apoiado sobre as referências nietzscheanas, os elementos primordiais da origem do coro trágico no canto do sátiro e o fator dionisíaco da arte na música dos enlutados Kobéua, em suas tristes melodias: "Os Kobéua, em união desconcertante aos olhos modernos, atribuíram ao ritual fúnebre também à dança do falo, onde exprimem drasticamente a ação fecundadora, representando mimicamente o acasalamento e a fecundação" (KOCHGRUNBERG, 2005, p. 521).

O que parece ser o ápice do ritual, pelo "descontrole sexual" dos dançarinos possessos, nos é descritos nestas impressões de Koch-Grunberg:

É coisa natural que os indígenas se dediquem a esta dança de falo com muito gosto e se inclinem a brincadeiras obscenas que propriamente não pertencem à cerimônia. Apesar disso, como eu já expliquei antes, esta dança é séria, porque representa um procedimento natural, e decente, de acordo com os conceitos do homem natural. Os espíritos de máscaras de demônios são imaginados como demônios de fecundação que estão sendo representados mimicamente a exercer o ato sexual, a fim de estimular o crescimento, amadurecimento e produção de frutos na natureza inteira, que está corporificada neles (KOCH-GRUNBERG, 2005, p. 522). 
Se aos olhos modernos o ritual toma aspecto desconcertante, aos antigos, segundo Burkert, "na indumentária do sátiro, a máscara e o falo andam sempre juntos” (BURKERT, 1993, p. 217). Logo, não só fazem parte da cerimônia - cai aqui a visão do homem teórico, imparcial -, numa análise estética nietzscheana, como formam o fechamento da tríade composta por danças, máscaras e falos, que vai de encontro com a antiga cultura grega sem o intermédio filológicofilosófico marcante na Origem da Tragédia, mas por meio do estudo histórico da religião grega no período arcaico e clássico de Walter Burkert.

\section{Conclusão}

O ponto chave, portanto, é confirmar o impulso dionisíaco do homem resguardado nas culturas tradicionais. Assim fez Nietzsche no caso da descrição da Tragédia grega: propõe-se a descoberta da dicotomia tão profundamente necessária à cultura trágica entre potência apolínea e a potência dionisíaca para fundamentar uma estética contemporânea.

O impulso apolíneo é o dominante em nossa atual cultura. Por um relato científico moderno de 1905 pudemos relacionar o teor dionisíaco do ritual, o que implica: primeiro, que o impulso dionisíaco não se apresenta somente na civilização grega, pelo contrário, está resguardado em civilizações, povos, tão antigos, como nos utilizados por Nietzsche, como em rituais de povos não-socratizados, em linguagem nietzscheana, primitivos aos olhos da ciência moderna, e que pode ser constatado tal impulso nesses povos; segundo, o impulso dionisíaco como chave para o conhecimento tradicional das culturas do alto rio Negro, conhecimento estético, que a contemporaneidade busca em culturas mortas, revividas através da historiografia e filologia.

Além de tudo, a necessidade do desprezo ao aparato apolíneo, presente em toda concepção de arte moderna, para entendermos a origem do conhecimento estético humano nos dias de hoje, onde até a arte está socratizada. "A ideia da tragédia é a do culto dionisíaco: a dissolução da individuação em outra ordem cósmica, a iniciação na crença na transcendência através dos terríveis meios geradores de pavor da existência" (NIETZSCHE,1993, p. 49), por isso,verifica-se a tradição da tragédia resguardada na cultura antiqüíssima dos Kobéua e Káua, segundo a descrição de Koch-Grunberg. 


\section{Notas}

1 Primeira parte do trabalho agraciada com menção honrosa no concurso nacional para graduandos em Filosofia, Dia Mundial da Filosofia no Brasil (www. diamundialdafilosofia.com.br), evento realizado pela UFRJ em parceria coma a UNESCO, e defendi -do publicamente na UFAM por meio do projeto A Amazônia dos Viajante e do Pojeto Idéias.

${ }^{2}$ Bildungsburger = pertencente à classe "bueguesia de educação" ou formação que era composta por profissionais autônomos, do baixo clero (sobretudo da igreja luterana) e servidores Beamte (públicos).

${ }^{3}$ Bildungsideal $=$ aperfeiçoamento da Seele (alma) de seus integrantes, via trabalho dedicado, o espírito autocontrole (discliplina, austeridade) e os estudos continuados (leitura) nos campos tanto das ciências (principalmente filosofia e história) como da poesia - ideal considerado pelos grandes filósofos-poetas alemães no século XVIII (de Lessing a Goethe)

\section{Referências}

BURKERT, Walter. Religião grega na época clássica e arcaica. Tradução M. J. Simões Loureiro. Lisboa: Fundação Calouste Gulbenkian, 1993.

FRANK, Erwin H. Viajar é preciso: Theodor Köch Grünberg e a Völkerkunde alemã do século XIX. In: Revista de Antropologia. São Paulo: USP, 2005, p. 560 a 579 .

JATOBÁ, Maria do Socorro da Silva. A Memória da Criação do Mundo. Manaus: Governo do Estado do Amazonas, 2001, p. 1-26.

KOCH-GRÜNBERG, Theodor. Dois anos entre os indigenas: viagens ao noroeste do Brasil (1903-1905). Tradução Pe. Casimiro Béksta. Edua/FSDB: Manaus, 2005.

NIETZSCHE, Friedrich. O Nascimento da tragédia. Tradução J. Guinsburg. São Paulo: Companhia das Letras, 2007.

NIETZSCHE, Friedrich. Introdução à Tragédia de Sófocles. Tradução Ernani Chaves. Rio de Janeiro: Jorge Zahar Editor, 2006.

NIETZSCHE, Friedrich. Música e Palavra. Tradução Oswaldo Giacoia Junior. In: Revista Discurso. São Paulo: Alameda, 2007, p. 167 a 181. 